\title{
Prolactinoma associated with an ependymoma in the fourth ventricle: A case report and review of the literature
}

\author{
JINLU YU ${ }^{1}$, HONGFA YANG ${ }^{1}$, LIMEI QU ${ }^{2}$ and YUNQIAN LI ${ }^{1}$ \\ Departments of ${ }^{1}$ Neurosurgery and ${ }^{2}$ Pathology, First Hospital of Jilin University, Changchun, Jilin 130021, P.R. China
}

Received August 15, 2014; Accepted April 21, 2015

DOI: $10.3892 / 01.2015 .3199$

\begin{abstract}
Pituitary adenoma associated with ependymoma in the fourth ventricle is a rare condition. In the present study, a 46-year-old man diagnosed with prolactinoma, who previously underwent two surgical procedures (one for the removal of a primary tumor and a second following its recurrence) developed a complication of ependymoma in the fourth ventricle. The presence of the ependymoma was confirmed by pathological analysis and the patient recovered well following two-phase surgical resection of the two tumors. The present study compared the probable cause of concurrent pituitary adenoma and ependymoma within the fourth ventricle with previous relevant studies. These comparisons were used to propose possible genomic and endocrine contributions for the development of the ependymoma from the pituitary adenoma.
\end{abstract}

\section{Introduction}

The presence of two distinct tumor types in the cranial cavity is rare; therefore, little is known regarding the development and progression of the disease in these cases. Pituitary adenomas comprise $\geq 90 \%$ of sellar masses and $10-15 \%$ of all intracranial neoplasm (1). So the coexistence of a pituitary adenoma and other intracranial tumors is not an uncommon finding, but the exact incidence of pituitary adenomas concomitant with other cranial tumors remains unclear. However, numerous reports have described incidences of pituitary adenoma concomitant with other types of cranial cavity tumor, such as meningioma (2-4), medulloblastoma (5), neurinoma (6), craniopharyngioma (7), astrocytoma (8) and glioma (9). While the etiology and underlying mechanisms for the development of these tumors remain unclear, it has been proposed that genomic and endocrine disorders, as well as radiation therapy and embryogenesis, may be important factors (2-11). The majority of pituitary adenomas concomitant with other cranial tumors are diagnosed by MRI or CT,

Correspondence to: Dr Yunqian Li, Department of Neurosurgery, First Hospital of Jilin University, 71 Xinmin Avenue, Changchun, Jilin 130021, P.R. China

E-mail: jlyu@jlu.edu.cn

Key words: pituitary adenoma, ependymoma, fourth ventricle current treatment strategies include the simultaneous or staged resection (12). At present, prolactinoma associated with ependymoma remains a rare finding. The current study describes a rare case of prolactinoma associated with ependymoma in the fourth ventricle.

\section{Case report}

Symptoms. A 46-year-old male patient exhibiting impaired vision and dizziness was admitted to the First Hospital of Jilin University (Changchun, China) on March 5, 2010. In 1999, the patient was diagnosed with prolactinoma in the sellar region and underwent surgical resection. In 2001, tumor recurrence was detected, with an hourglass-shaped lesion observed in the sellar region as a low-density signal on T1-weighted magnetic resonance imaging (MRI). Furthermore, upward displacement of the optic chiasm occurred (Fig. 1A) and the tumor was observed to have invaded the cavernous sinus (Fig. 1B). For treatment, the patient underwent transcranial surgery in combination with Gamma Knife therapy (center dose, 45 Gy; peripheral dose, $20 \mathrm{~Gy}$ ). The patient recovered well; however, tumor recurrence was detected in 2010, as described below.

Presenting clinical symptoms included dizziness with progressive impaired vision. A nervous system examination detected vision in the left and the right eyes of 4.3 and 4.7 diopters, respectively (normal range, 5.0-5.3 diopters). Primary optic atrophy at the fundus and binocular temporal hemianopsia were also observed. Furthermore, an MRI scan detected lesions in the sellar region and fourth ventricle that were associated with a low-density signal on T1-weighted imaging (T1WI) and a relatively high-density signal detected on T2WI, respectively. The lesion volumes were $4.6 \times 4.7 \times 2.3 \mathrm{~cm}$ and $3.5 \times 3.5 \times 3.0 \mathrm{~cm}$, respectively. Additionally, the fourth ventricle was observed to expand in response to compression, but was not completely blocked (Fig 2A-D). Hormone levels were detected to be within the normal ranges, with the exception of prolactin at 1,021.40 mIU/1 (normal range, $70.81-566.46 \mathrm{mIU} / \mathrm{l}$ ) and growth hormone at $0.50 \mathrm{ng} / \mathrm{ml}$ (normal range, 1.0-5.0 ng/ml). Considering the medical history, MRI and laboratory examination results, the patient was diagnosed with prolactinoma associated with ependymoma in the fourth ventricle.

Treatment. Resection of the tumors in the fourth ventricle and the sellar region was conducted in two phases. In phase I, 
A

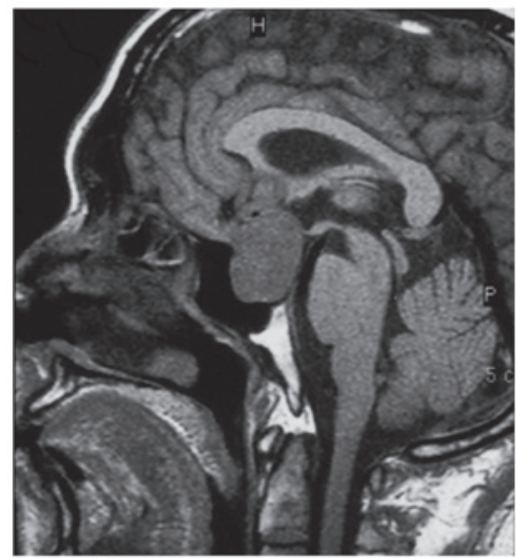

B

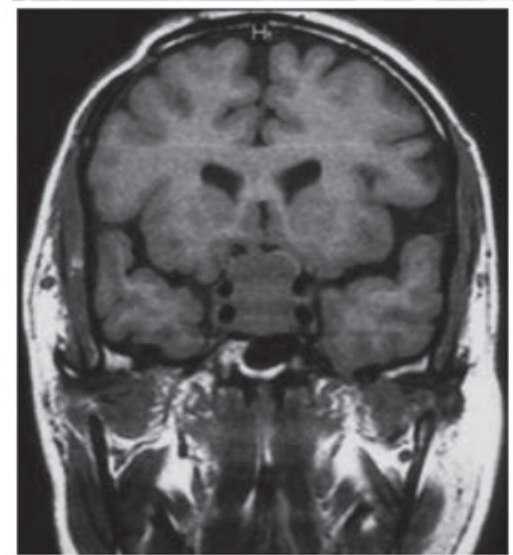

Figure 1. Magnetic resonance imaging of the pituitary adenoma prior to resection, revealing (A) an hourglass-shaped lesion in the sellar region exhibiting a low-density signal on T1-weighted imaging. In addition, the optic chiasm appears elevated and (B) the tumor has invaded the cavernous sinus.

surgical resection of the ependymoma in the fourth ventricle was performed. The tumor was observed to originate from, and to be adhered to, the bottom of the fourth ventricle, with invasion towards the mesopore. The tumor was faint red in color with a moderately tough texture and an abundant blood supply. The tissue was fixed with formalin for 12-48 hours, then following gross examination the tissue was embedded in paraffin and cut to the slides using the cryostat (Leica Biosystems Nussloch GmbH, Wetzlar, Germany). Hematoxylin/eosin (H/E) staining (Leica Biosystems Nussloch $\mathrm{GmbH}$ ) was used to visualize the tissue architecture and a microscope (CX22, Olympus Corporation, Tokyo, Japan) was used to capture representative images. Pathological examination with $\mathrm{H} / \mathrm{E}$ staining detected densely arranged tumor cells with certain clusters forming cell masses. The latter were characterized by round or ovoid nuclei, dense chromatin and a slim nucleolus. Together, these observations led to a diagnosis of ependymoma (World Health Organization class II (13); Fig. 3A and B). Following the surgery, the patient recovered well and no complications occurred. Furthermore, postoperative MRI scans demonstrated that the tumor was completely resected and the fourth ventricle was relieved from obstruction (Fig. 4A and B).

The second surgical procedure (phase II) to remove a pituitary adenoma in the sellar region was performed 10 days after the phase I surgery. The tumor was observed to be dull red in color, soft in texture and have a relatively abundant blood
A

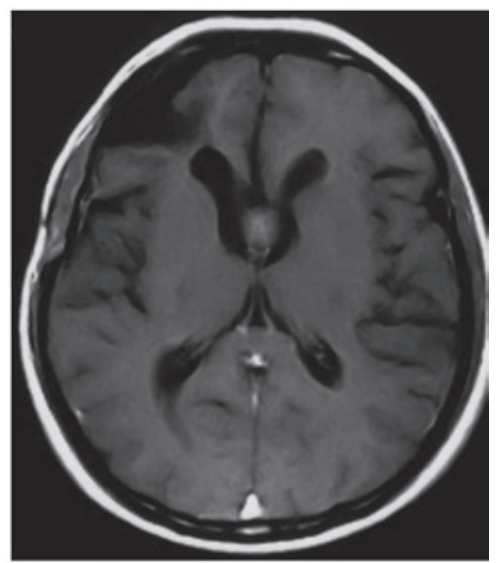

B

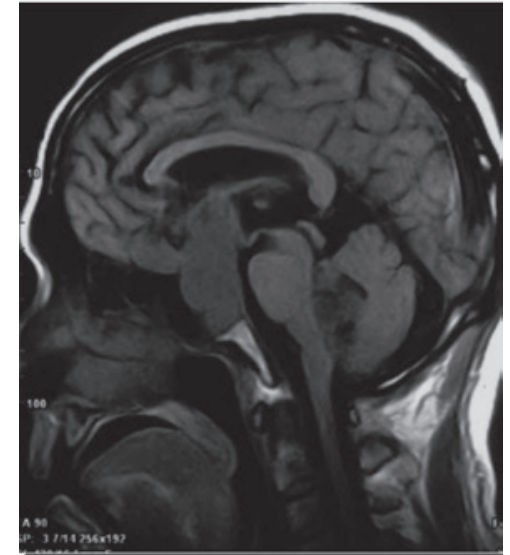

C

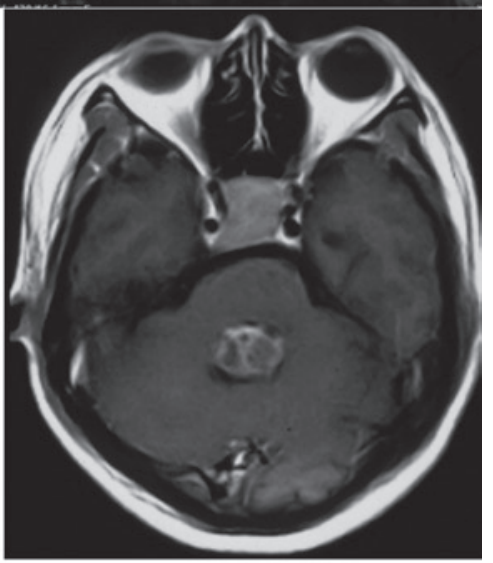

D

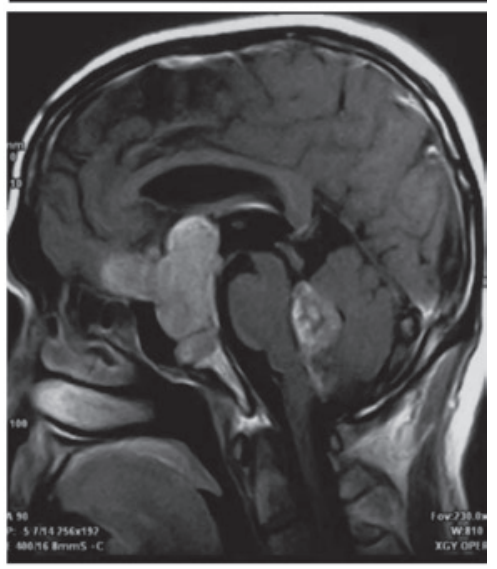

Figure 2. Magnetic resonance imaging of a pituitary adenoma associated with ependymoma in the fourth ventricle prior to resection. Lesions in the $(A)$ sellar region $(4.6 \times 4.7 \times 2.3 \mathrm{~cm})$ and $(B)$ ventricles $(3.5 \times 3.5 \times 3.0 \mathrm{~cm})$ were observed as low-density T1-weighted imaging (T1WI) and relatively high-density T2WI signals, respectively. The fourth ventricle expanded in response to compression, but was not completely blocked. (C) and (D) represent enhanced scans of (A) and (B), respectively. 

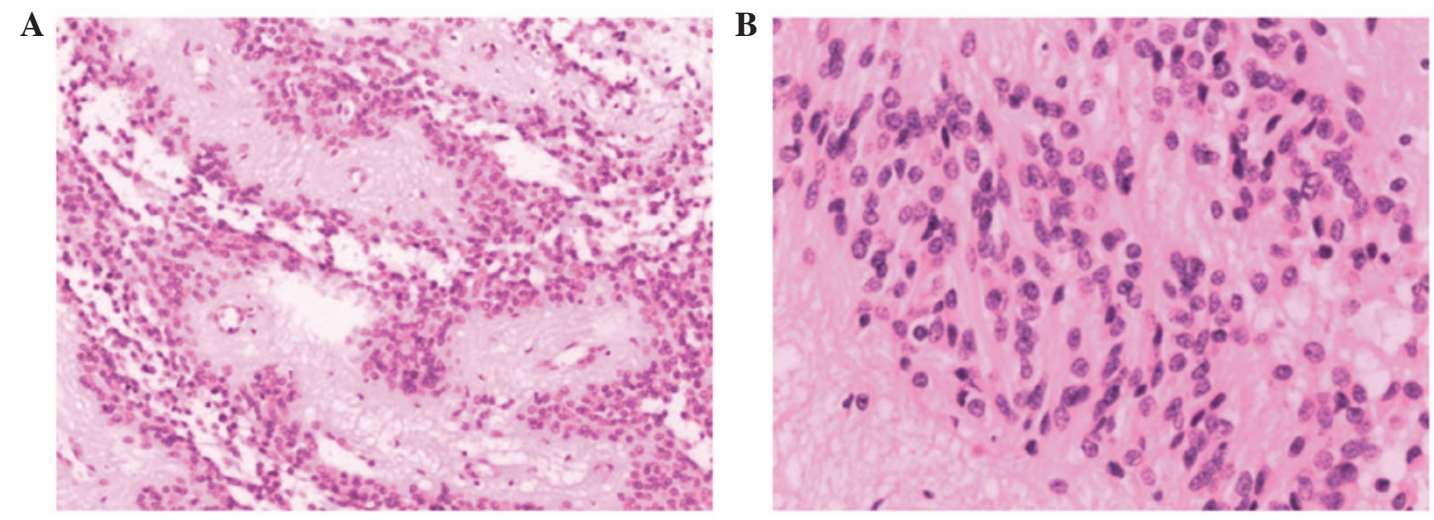

Figure 3. Hemotoxylin and eosin staining of the fourth ventricle. (A) Densely arranged tumor cells, some forming cell masses (magnification, x200), (B) exhibiting round or ovoid nuclei, dense chromatin and slim nucleoli (magnification, x400). The tumor was diagnosed as an ependymoma (World Health Organization class II).
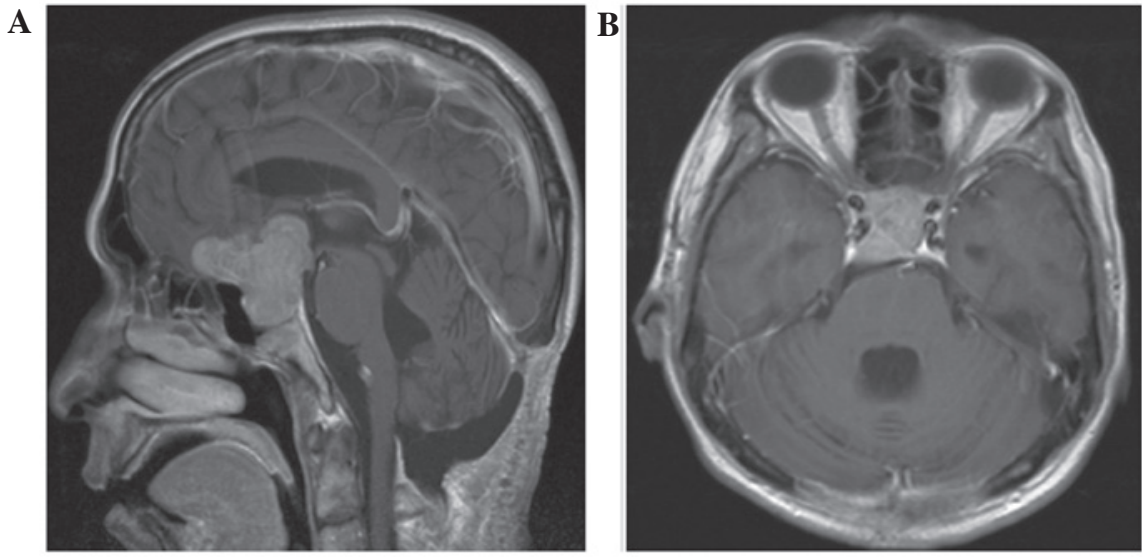

Figure 4. (A) Sagittal and (B) axial magnetic resonance imaging scans following resection of the ependymoma.
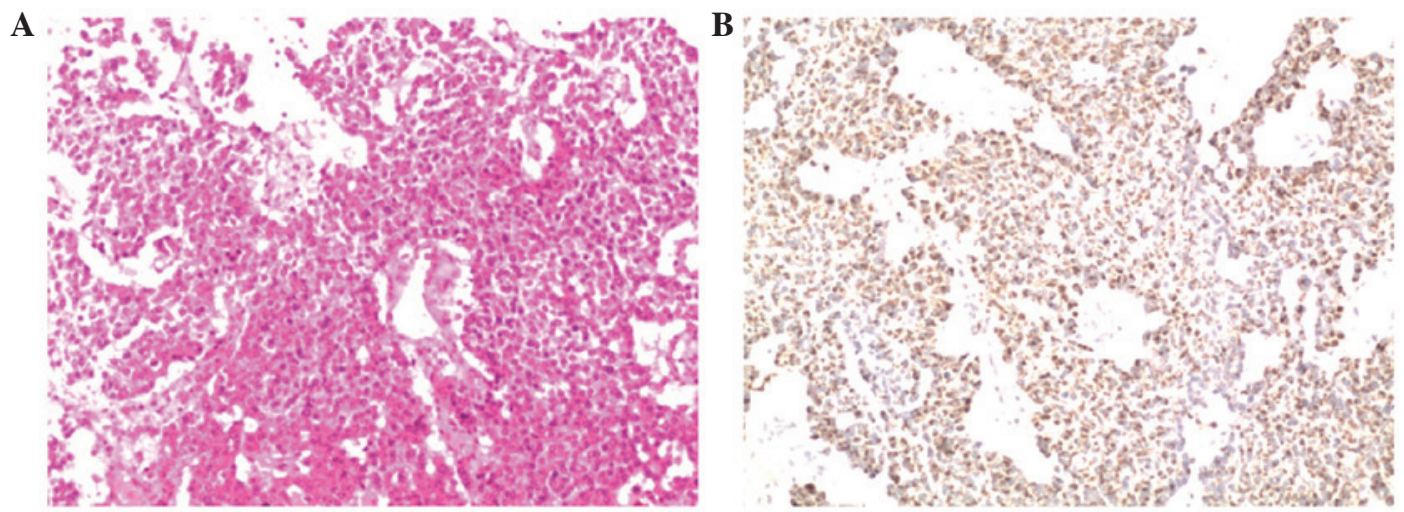

Figure 5. Pathological analysis of lesions that developed in the sellar region. (A) Tumor cells detected by hemotoxylin and eosin staining were diffusely distributed with minimal extracellular matrix. (B) Immunohistochemical assays detected prolactin expression in the in tumor tissues, resulting in a diagnosis of prolactinoma. Magnification, x200.

supply. Based on $\mathrm{H} / \mathrm{E}$ staining, the tumor cells were observed to be diffusely distributed with minimal extracellular matrix. Additional immunohistochemical assays detected expression of prolactin in the tumor. Together, these characteristics led to a diagnosis of prolactinoma (Fig. 5A and B). Following the surgical procedure, the patient received Gamma Knife therapy and recovered well; the symptoms derived from the mass effects of the tumors improved.

\section{Discussion}

The presence of two different tumor types in the cranial cavity of a single patient is rare (2-6). However, of the cases reported thus far, meningioma associated with glioma is the most frequently described, followed by meningioma associated with pituitary adenoma and neurinoma $(13,14)$. Subsequent to a 1995 study by Love et al (15) that reported a case of pituitary 
adenoma associated with meningioma, cases of pituitary adenoma associated with medulloblastoma (5), neurinoma (6), craniopharyngioma (7), astrocytoma (8) and glioma (9) have been described. However, to the best of our knowledge, no report has, thus far, described a case of pituitary adenoma associated with an ependymoma in the fourth ventricle. Therefore, the present study of prolactinoma associated with ependymoma in the fourth ventricle represents a unique case.

Similar genetic mutations have been identified in pituitary adenomas and ependymomas, and these mutations appear to be essential in the formation and progression of the two tumor types $(10,13)$. Furthermore, in neurofibroma (type 2$)$, a mutation in NF2, a tumor suppressor gene located at chromosome position $22 q 12$, has been associated with the formation of various intracranial tumors, including meningiomas, gliomas and vestibular schwannomas (16). In addition, Furtado et al $(11,15)$ reported three cases of pituitary adenoma associated with two cases of glioma and one case of meningioma, and demonstrated that these tumors resulted from gene mutations common to both tumor types in each case. However, various gene mutations have been identified in pituitary adenomas and other intracranial tumors, such as gliomas and meningiomas, that have different roles in each tumor type. For example, gene mutations identified in pituitary adenomas include the deletion of segments from chromosomes 1p, 2q, 4, 5, 6, 11q, 12q, 13q and $18 \mathrm{q}(10,17)$, and the overexpression of genes on chromosomes 9q, 16p, 17p, 19 and 20q $(16,18)$. Furthermore, there have been a greater number of gain-of-function than loss-of-function mutations associated with pituitary adenomas $(10,16,17)$. In ependymomas, deletion of chromosome 22 , and overexpression of genes on chromosomes 1, 6, 7, 9-13, 16, 17, 19 and 20, have been detected (19). Therefore, according to the aforementioned studies, overexpression of genes on chromosomes 17 and 19 may be common genomic disorders associated with pituitary adenomas and ependymomas. However, additional studies are required to clarify this.

Hypotheses regarding the formation of intracranial tumors induced by radiation therapy have been confirmed in specific cases of glioblastoma, meningioma, sarcoma, astroma and ependymoma (20-23). Additionally, there are reports regarding the development of intracranial tumors, such as meningiomas $(24,25)$, primitive neuroectodermal tumors (26), gliomas $(20,27)$ and ependymomas $(28)$ in response to radiation therapy for pituitary adenoma. Similarities between the aforementioned cases have been reviewed $(29,30)$ and include the following: i) The development of secondary tumors within regions exposed to radiation; ii) the formation of secondary tumors following radiation therapy; iii) tissue origin of the primary tumors distinct from the tissue origin of the secondary tumors; iv) pathogenic genes identified in primary tumors differing from those of the secondary tumors; and v) a latency period of secondary tumor development of $>5$ years. In regard to the present case, we hypothesize that the ependymoma present in the fourth ventricle had a low probability of being induced by the Gamma Knife radiation therapy used to treat the pituitary adenoma, as the radiation was focused on the tumor in the sellar region, which is a considerable distance from the ventricles. As a result, the radiation dose that the fourth ventricle received would be expected to be low. Therefore, it is proposed that induction of the ependymoma in the present case was more likely to be the result of gene mutations in chromosomes 17 and 19 that are common to pituitary adenomas and ependymomas.

Amit et al (6) and Furtado et al (11) have previously speculated that different intracranial tumors may originate from cellular remnants left following embryogenesis. This hypothesis appears to be supported by a case of craniopharyngioma associated with pituitary adenoma and notochordoma reported by Shishkina et al (31). However, the current authors propose that embryogenesis was not involved in the present case, as these two tumors were different in cell origin.

In the clinic, certain cases of pituitary adenoma have been identified to be induced by factors secreted by the pituitary adenoma itself. For example, Curto et al (10) reported a case of pituitary adenoma associated with meningioma and an aneurysm, and demonstrated that growth hormones may have had a role in tumor development. Similarly, Fernandez et al (8) reported a case of pituitary adenoma associated with astroma in which insulin-like growth factor was involved. Somatostatin receptors (32) and epidermal growth factor receptors $(33,34)$ are also expressed in pituitary adenomas and ependymomas, and may have a role in inducing the formation of pituitary adenomas and ependymomas.

In conclusion, the present study reports a rare case of pituitary adenoma associated with ependymoma in the fourth ventricle. Considering the characteristics of the current patient in association with previous case reports involving two tumors within the same cranial cavity, it is proposed that the basis of these disorders includes a genomic and endocrine component.

\section{References}

1. Sautner D, Saegar W and Ludecke DJ: Tumors of the sellar region mimicking pituary adenomas. Exp Clin Endocrinol 101: 283-289, 1993.

2. Abs R, Parizel PM, Willems PJ, Van de Kelft E, Verlooy J, Mahler C, Verhelst J, Van Marck E and Martin JJ: The association of meningioma and pituitary adenoma: Report of seven cases and review of the literature. Eur Neurol 33: 416-422, 1993.

3. da Costa LB Jr, Riva-Cambrin J, Tandon A and Tymianski M: Pituitary adenoma associated with intraventricular meningioma: Case report. Skull Base 17: 347-351, 2007.

4. Prevedello DM, Thomas A, Gardner P, Snyderman CH, Carrau RL and Kassam AB: Endoscopic endonasal resection of a synchronous pituitary adenoma and a tuberculum sellae meningioma: Technical case report. Neurosurgery 60 (Suppl 2): E401, 2007.

5. Samaras V, Samaras E, Stergiou I, Konstantopoulou P, Arnaoutoglou C, Arnaoutoglou M, Varsos V and Barbatis C: Simultaneous occurrence of cerebellar medulloblastoma and pituitary adenoma: A case report. Cases J 1: 175, 2008.

6. Amit A, Achawal S and Dorward N: Pituitary macro adenoma and vestibular schwannoma: A case report of dual intracranial pathologies. Br J Neurosurg 22: 695-696, 2008.

7. Moshkin O, Scheithauer BW, Syro LV, Velasquez A, Horvath E and Kovacs K: Collision tumors of the sella: craniopharyngioma and silent pituitary adenoma subtype 3: Case report. Endocr Pathol 20: 50-55, 2009.

8. Fernandez A, Karavitaki N, Ansorge O, Fazal-Sanderson V and Wass JA: Acromegaly and anaplastic astrocytoma: Coincidence or pathophysiological relation? Pituitary 11: 325-330, 2008.

9. Mangiola A, De Bonis P, Guerriero M, Pompucci A and Anile C: Gliomatosis cerebri and pituitary adenoma: Case report and literature review. J Neurooncol 74: 321-324, 2005.

10. Curto L, Squadrito S, Almoto B, Longo M, Granata F, Salpietro F, Torre ML, Marini F, Trimarchi F and Cannavo S: MRI finding of simultaneous coexistence of growth hormone-secreting pituitary adenoma with intracranial meningioma and carotid artery aneurysms: Report of a case. Pituitary 10: 299-305, 2007. 
11. Furtado SV, Venkatesh PK, Ghosal N and Hegde AS: Coexisting intracranial tumors with pituitary adenomas: Genetic association or coincidence? J Cancer Res Ther 6: 221-223, 2010.

12. Jaiswal S, Vij M, Jaiswal AK, Chand G, Behari S and Kumarjain V: Ossifying pituary adenoma co-existing with astrocytoma and pituary adenoma associated with gangliocytoma: Two unusual conditions. Turk Neurosurg 22: 127-133, 2012.

13. Louis DN, Ohgaki H, Wiestler OD, et al: The 2007 WHO classification of tumours of the central nervous system. Acta Neuropathol 114: 97-109, 2007.

14. Love JG and Blackburn CM: Association of intracranial meningioma with pituary adenoma; reported of successfully treated case. Minn Med 38: 335-336, 1955

15. Furtado SV, Dadlani R, Ghosal N, Mahadevan A, Shankar SK and Hegde AS: Co-existing thyrotropin secreting pituitary adenoma and low grade glioma: Clinical considerations and literature review. J Neurosurg Sci 53: 71-75, 2009.

16. Asthagiri AR, Parry DM, Butman JA, Kim HJ, Tsilou ET, Zhuang Z and Lonser RR: Neurofibromatosis type 2. Lancet 373: 1974-1986, 2009.

17. Chesnokova V, Zonis S, Ben-Shlomo A, Wawrowsky K and Melmed S: Molecular mechanisms of pituitary adenoma senescence. Front Horm Res 38: 7-14, 2010.

18. Szymas J, Schluens K, Liebert W and Petersen I: Genomic instability in pituitary adenomas. Pituitary 5: 211-219, 2002.

19. Collins VP: Brain tumours: Classification and genes. J Neurol Neurosurg Psychiatry 75 (Suppl 2): ii2-ii11, 2004.

20. Anderson JR and Treip CS: Radiation-induced intracranial neoplasms. A report of three possible cases. Cancer 53: 426-429, 1984.

21. Kim JH, Brown SL, Jenrow KA and Ryu S: Mechanisms of radiation-induced brain toxicity and implications for future clinical trials. J Neurooncol 87: 279-286, 2008.

22. Pettorini BL, Park YS, Caldarelli M, Massimi L, Tamburrini G and Di Rocco C: Radiation-induced brain tumours after central nervous system irradiation in childhood: A review. Childs Nerv Syst 24: 793-805, 2008.

23. Weinstein JL, Ayyanar K and Watral MA: Secondary neoplasms following treatment for brain tumors. Cancer Treat Res 150 239-273, 2009

24. Honegger J, Buchfelder M, Schrell U, Adams EF and Fahlbusch R The coexistence of pituitary adenomas and meningiomas: Three case reports and a review of the literature. Br J Neurosurg 3 : 59-69, 1989.
25. Partington MD and Davis DH: Radiation-induced meningioma after treatment for pituitary adenoma: Case report and literature review. Neurosurgery 26: 329-331, 1990.

26. Bhansali A, Banerjee AK, Chanda A, Singh P, Sharma SC, Mathuriya SN and Dash RJ: Radiation-induced brain disorders in patients with pituitary tumours. Australas Radiol 48:339-346 2004.

27. Tsang RW, Laperriere NJ, Simpson WJ, Brierley J, Panzarella T and Smyth HS: Glioma arising after radiation therapy for pituitary adenoma. A report of four patients and estimation of risk. Cancer 72: 2227-2233, 1993.

28. Alexander MJ, DeSalles AA and Tomiyasu U: Multiple radiation-induced intracranial lesions after treatment for pituitary adenoma. Case report. J Neurosurg 88: 111-115, 1998.

29. Carlson ML, Babovic-Vuksanovic D, Messiaen L, Scheithauer BW, Neff BA and Link MJ: Radiation-induced rhabdomyosarcoma of the brainstem in a patient with neurofibromatosis type 2. J Neurosurg 112: 81-87, 2010.

30. Sheehan J, Yen CP and Steiner L: Gamma knife surgery-induced meningioma. Report of two cases and review of the literature. J Neurosurg 105: 325-329, 2006.

31. Shishkina VL, Kasumova SIu, Snigireva RIa and Miakota AE: Craniopharyngioma associated with pituitary adenoma and chordoma of Blumenbach's clivus. Zh Vopr Neirokhir Im N N Burdenko (6): 52-54, 1981 (In Russian).

32. Guyotat J, Champier J, Jouvet A, Signorelli F, Houzard C, Bret P, Saint Pierre G and Fevre Montange M: Differential expression of somatostatin receptors in ependymoma: Implications for diagnosis. Int J Cancer 95: 144-151, 2001.

33. Mendrzyk F, Korshunov A, Benner A, Toedt G, Pfister S, Radlwimmer B and Lichter P: Identification of gains on $1 \mathrm{q}$ and epidermal growth factor receptor overexpression as independent prognostic markers in intracranial ependymoma. Clin Cancer Res 12: 2070-2079, 2006.

34. Vlotides G, Siegel E, Donangelo I, Gutman S, Ren SG and Melmed S: Rat prolactinoma cell growth regulation by epidermal growth factor receptor ligands. Cancer Res 68: 6377-6386, 2008. 